\section{Journal of Anatolian Environmental and Animal Sciences \\ (Anadolu Çevre ve Hayvancılık Bilimleri Dergisi) \\ Doi: https://doi.org/10.35229/jaes.605597}

\title{
Nazik Gölü Balıkçılığı Üzerine Bir Araştırma
}

\section{Adem Sezai BOZAOĞLU ${ }^{1 *} \quad$ Mustafa AKKUŞ ${ }^{1}$}

${ }^{1}$ Van Yüzüncü Yıl Üniversitesi Su Ürünleri Fakültesi, 65080, Zeve Kampüsü, Van, Türkiye,
*(D): https://orcid.org/0000-0003-4078-5159, (iD: https://orcid.org/0000-0002-8900-9495

Öz: Bu çalışma Nazik Gölü balıkçılık faaliyetlerinin belirlenebilmesi için Eylül - Aralık 2018 tarihleri arasında, aktif olarak çalışan 18 balıkçı ile yüz yüze anket görüşmesi yapılarak gerçekleştirilmiştir. Nazik Gölü’nde balık avcılığında 0,4 donam faktörüyle donatılmış 140 mm

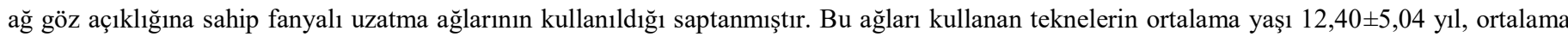

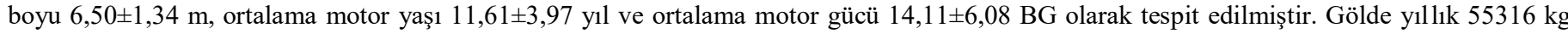
balık avladığı belirlenmiştir. Teknelerde çalışan tayfaların ortalama sayısı 1,22 $\pm 0,73$ olarak tespit edilmiştir. Tayfaların \%83'ünün sürekli \%17'sinin ise arada bir, çalıştı̆̆ saptamıştır. Balıkçıların \%78'inin ilkokul, \%22'sinin ortaokul mezunu olduğu belirlenmiştir. Ayrıca çalışan balıkçılar içerisinde lise veya üniversite mezununun olmadığı tespit edilmiştir. Balıkçılık yapanların ortalama yaşının $36,44 \pm 10,04$ olduğu,

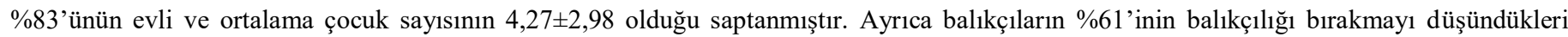
tespit edilmiştir. Balıkçıların en önemli sorunlarının kaçak avcılık ve avladıkları balığın düşük fiyata satılması olduğu saptanmıştır. Araştırma sonucuna göre balıkçıların hepsinin ikinci bir işinin olduğu belirlenmiştir. Özellikle sezonun kapalı olduğu dönemlerde çoğunluğunun inşaatta işçi olarak çalıştığı, bunun yanında hayvancılık ve tarımla da uğraştıkları tespit edilmiştir.

Anahtar sözcükler: Balıkçılık, Nazik gölü, sosyo ekonomik yapı.

\section{An Investigation on Lake Nazik Fishery}

Abstract: This study was conducted in September - December 2018 by conducting face - to - face questionnaire interviews with 18 active fishermen in order to find out the fishing activities of Lake Nazik. It was found that trammel nets with a mesh size of $140 \mathrm{~mm}$ equipped with a 0.4 hanging ratio were used for fishing in Lake Nazik. The average age of the boats using these nets was between $12.40 \pm 5.04$ years, while the length was between $6.50 \pm 1.34 \mathrm{~m}$. On the other hand, it was found out that the average motor age was between $11.61 \pm 3.97$ years and the average motor power was between $14.11 \pm 6.08 \mathrm{BG}$. It was revealed that $55316 \mathrm{~kg}$ of fish are caught in the lake annually. The average number of crews working on boats was found to be between $1.22 \pm 0.73$. It was found that $83 \%$ of the crews worked continuously, and $17 \%$ worked occasionally. $78 \%$ of the fishermen were primary school graduates, and $22 \%$ were secondary school graduates. In addition, it was found that there were no high school or university graduates among the working fishermen. The average age of the fishermen was between $36.44 \pm$ $10.04,83 \%$ of them were married and the average number of children was $4.27 \pm 2.98$. In addition, $61 \%$ of fishermen reported that they were thinking to stop fishing. The most important problems of the fishermen were illegal fishing and the low price at which they sold fish. According to the results of the research, it was revealed that all fishermen had a second job. Especially during the off season, it was found that most of them worked as construction workers, and they were also engaged in animal husbandry and agriculture. 


\section{GİRIŞ}

Nazik Gölü, 46 km² lik yüzölçümü ile Van Gölü havzasında bulunan en büyük tatlı su kaynağıdır. Gölde yerli tür olarak Siraz (Capoeta capoeta) ve inci kefali (Alburnus tarichi) ile göle sonradan aş1lanan sazan (Cyprinus carpio) ve havuz balığı (Carassius carassius) yaşamaktadır (Şen, 2001). Nazik Gölü, Van Gölü havzasında Van Gölü’nden sonra en fazla avcılık yapılan alandır. Türkiye'deki $30139000 \mathrm{~kg}$ 'lık iç sular avcılık miktarının 3528000 kg'ını siraz ve sazan oluşturmaktadır. Buda avcılık miktarının yaklaşık olarak \%10'udur (TÜİK, 2018). Bu miktarın \% 2'si Nazik Gölü’nden karşılanmaktadır. Nazik Gölü'nde balık avcılığında kullanılan tek av aracı fanyalı uzatma ağlarıdır. Uzatma ağları aynı zamanda, ülkemiz kıyı balıkçığında kullanılan en önemli pasif av aracıdır. 2018 yılı verilerine göre Türkiye'de 7556 adet uzatma ağı teknesi vardır. Bu teknelerin 2831 adedi iç sularda bulunmaktadır (TÜİK, 2018). Bu teknelerin 25'i Nazik Gölü'nde avcıllk yapmaktadır (SUBİS, 2018). Türkiye'de balıkçılık genel olarak büyük ölçekli ve küçük ölçekli olmak üzere iki kategoride sınıflandırılmaktadır. Nazik Gölü balıkçılığı, küçük ölçekli balıkçılık gurubunda yer almaktadır. Bu tip balıkçılık, az kazandıran ancak birçok insana iş sağlayan ve geleneklerin hakim olduğu bir iş koludur. Balıkçılık faaliyetlerinin, Nazik Gölü gibi, küçük ölçekli teknelerle gerçekleştirildiği yerlerde, etkin ve bilimsel temellere dayanan balıkçılık yönetimin oluşturulması sektörün sürdürülebilirliği açısından hayati önem taşımaktadır (Karakuş, 2015). Balıkçılık yönetiminin başarısı, sağlıklı veri toplanması ve bunların doğru metotlarla işlenmesine bağlıdır. $\mathrm{Bu}$ verilerin önemli bir bölümünü biyolojik veriler, av araç gereçleriyle ilgili veriler, demografik ve sosyo-ekonomik veriler oluşturmaktadır. Ancak Türkiye'de balıkçılıkla ilgili bölgesel ve ulusal düzeyde veri kaynakları oldukça sınırlıdır ve çoğu zaman bu veriler güvenilir olmaktan uzaktır (Ünal vd., 2001). Bir bölgedeki balıkçılık yapan kişi ve balıkçı tekne sayısı, av araçları çeşitliliği ve kapasitesi, avlanan türler ve av miktarları, en az avcılığı yapılan türlerin stok bilgileri kadar gerekli ve önemlidir. $\mathrm{Bu}$ tür verilerin sürekli alınması ve izlenmesi gerekir (Tokaç vd., 2007). Bununla beraber balıkçılık kaynaklarının yönetilmesinde etkin av gücünün bilinmesi, stokların ne kadar balıkçı teknesiyle ne tür bir avcılık baskısına maruz kaldığının ortaya konulması, sadece balıkçılık kaynaklarının korunması ve sürdürülebilir kullanımını temin etmesi açısından önemli olmayıp aynı zamanda balıkçının gelirini koruması ve varlığını sürdürmesi açısından da önemlidir. Bu nedenle, her bir bölge için balıkçılık haritalarının çıkarılması, envanter çalışmalarının tamamlanması ve balıkçılıkla ilgili çalışmaların yanı sıra balıkçılarla ilgili çalışmalarında yürütülmesi gerekmektedir (Ünal, 2003). Sosyo-ekonomik açıdan büyük öneme sahip küçük ölçekli balıkçılığın sürdürülebilirliğinin sağlanması için etkin ve doğru yönetim politikalarına ihtiyaç vardır (Karakuş, 2015). Bu çalışmada, Nazik Gölü balıkçılığının sosyo-ekonomik yapısı, kullanılan av araçları ile balıkçı teknelerinin özellikleri ve gölde avlanan balık miktarı belirlenmiştir. Ayrıca mevcut sorunlar tespit edilerek çözüm önerileri sunulmuştur.

\section{MATERYAL VE METOT}

Çalışma Van Gölü havzasının önemli balıkçılık alanlarından olan Nazik Gölü’nde yürütülmüştür (Şekil 1). Nazik Gölü, Doğu Anadolu Bölgesi'nde, Van Gölü'nün Kuzeybatısında yer almaktadır. Göl Bitlis ilinin Ahlat ilçesi sınırları içerisinde konumlanmıştır. Su toplama havzası 149 $\mathrm{km}^{2}$ ve yüzölçümü yaklaşık $46 \mathrm{~km}^{2}$ dir. Gölün en uzun doğubatı doğrultusu $11 \mathrm{~km}$ kadardır. Nazik Gölü’nün, muhtemelen Bilican Dağı'ndan gelen lav akıntılarının gölün yerleştiği vadinin önünü kapatmasıyla oluştuğu tahmin edilmektedir (Alkışlar vd., 2017).

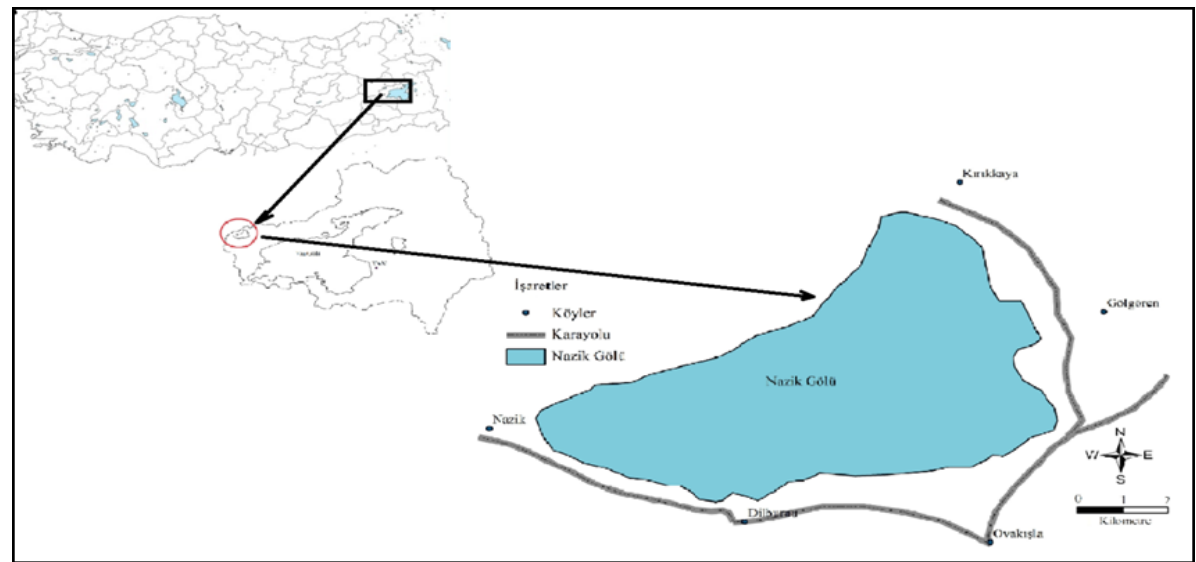

Şekil 1. Araştırma alanı.

Çalışma kapsamında, Eylül-Aralık 2018 ayları arasında, Nazik Gölü’nde aktif olarak çalışan 18 tekne sahibi ile yüz yüze anket görüşmesi yapılmıştır. Çalışmada (Özbilgin vd., 2009) tarafindan hazırlanan anket 
kullanılmıştır. Anket çalışmasında gölde avlanan balık miktarı, avcılık yapılan gün sayısı, tayfaların sayısı ve çalışma durumları, balıkçıların eğitim durumları, medeni durumları, barınma durumu, balıkçılığa nasıl başladıkları, bu işi bırakmayı düşünüp düşünmedikleri, sosyal güvence durumları, çocuklarının bu işi yapmalarını isteyip istemedikleri ve bu işten başka bir iş yapıp yapmadıkları sorularına cevap aranmıştır. Ayrıca gölde kullanılan fanyalı uzatma ağlarının teknik özellikleri, avcılık operasyon bilgileri ile bu ağları kullanan teknelerin özellikleri yerinde belirlenmiştir. Kullanılan ağın teknik özellikleri FAO standartlarına göre çizilmiştir. Ağların teknik özelliklerinin çiziminde “Corel Draw 12” programı kullanılmıştır.

\section{BULGULAR}

Fanyalı Uzatma Ăğının Teknik Özellikleri: Nazik Gölü'nde balık avcılığında fanyalı uzatma ağlar kullanılmaktadır. Fanyalı uzatma ağları temel olarak tor, fanya, mantar yaka ve kurşun yakadan oluşmaktadır. Bu ağların bir postası, $80 \mathrm{~m}$ uzunluğunda ve torun her iki tarafinda fanya bulunmaktadır. Ağlarda kullanılan torlar; 210 denye 3 numara ip kalınlığında, Poliamid (PA), 140 mm tam göz boyunda ve ağın derinliği 100 adet gözden oluşmaktadır. Fanyalar ise; 210 denye 9 numara ip kalınlığında, PA, 450 $\mathrm{mm}$ tam göz boyunda ve 5 göz derinliğindedir. Mantar yakada $80 \mathrm{~m}$ uzunluğunda Polipropilen (PP) $5 \mathrm{~mm}$ çaplı ana halat ile 79 adet plastik (Pl) 3 numara siyah renkli yüzdürücü kullanılmaktadır. Kurşun yakada ise; $82 \mathrm{~m}$ uzunluğunda Polipropilen (PP) $5 \mathrm{~mm}$ çaplı ana halat ve PP $4 \mathrm{~mm}$ çaplı koşma halatı ile 119 adet 50 gr lik kurşun (PB) kullanılmaktadır. Bu uzatma ağı mantar yakaya \%40, kurşun yakaya ise \%41 donam faktörü ile donatılmıştır. Mantar yakada çako boyu $168 \mathrm{~mm}$, kurşun yakada ise $172 \mathrm{~mm}$ olduğu tespit edilmiştir (Şekil 2).

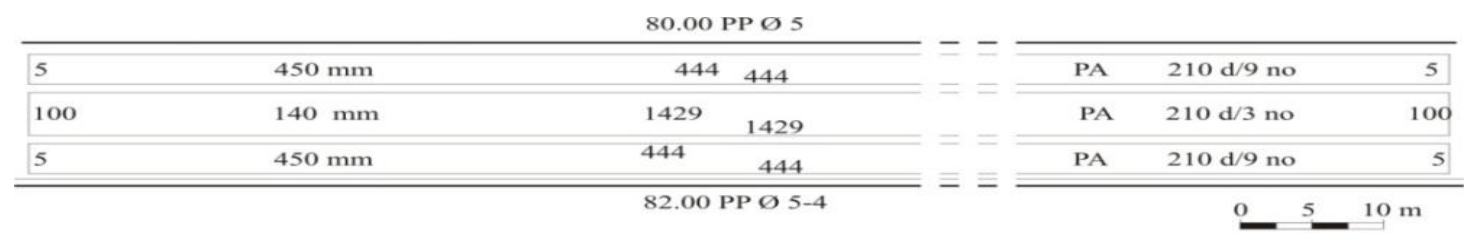

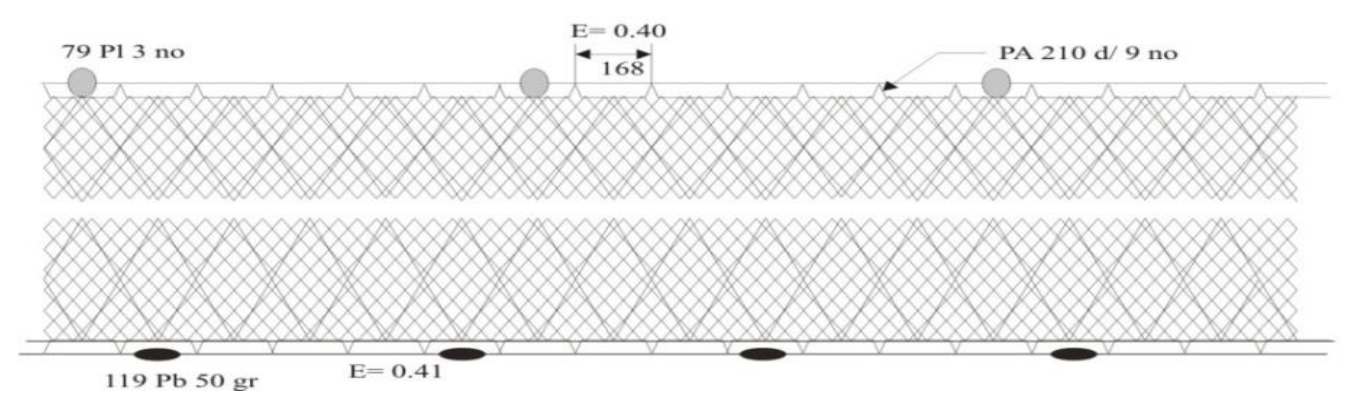

Şekil 2. Fanyalı uzatma ağının teknik planı.

Balıkçı Teknelerinin Özellikleri: Nazik Gölü’nde aktif olarak çalışan tekneler sacdan yapılmış olup, teknelerin ortalama yaşı $12,40 \pm 5,04 \mathrm{y} 1$, ortalama boyu $6,50 \pm 1,34 \mathrm{~m}$, ortalama motor yaşı $11,61 \pm 3,97$ yıl ve ortalama motor gücü 14,11 $\pm 6,08$ BG olarak tespit edilmiştir (Tablo 1).

Tablo 1. Nazik Gölü balıkçı teknelerinin özellikleri.

\begin{tabular}{ll}
\hline Teknelerin Özellikleri & Ort \pm SH \\
\hline Tekne Yaşı (yıl) & $12.40 \pm 5.04$ \\
Tekne Boyu (m) & $6.50 \pm 1.34$ \\
Makine Yaşı (yıl) & $11.61 \pm 3.97$ \\
Makine Gücü (HP) & $14.11 \pm 6.08$ \\
\hline
\end{tabular}

Aylara Göre Avlanan Balık Miktarı: Nazik Gölü'nde yapılan anket sonuçlarına göre 18 teknenin yıllık $55316 \mathrm{~kg}$ balık avladığı tespit edilmiştir. Günlük avladıkları ortalama balık miktarı değerlendirildiğinde, en yüksek avcılık miktarı Eylül'de $503 \pm 16,05 \mathrm{~kg}$, en düşük avcılık miktarı ise $10 \pm 1,42 \mathrm{~kg}$ ile Mart'ta gerçekleşmiştir. 15 Mayıs - 15 Ağustos tarihleri arasında gölde balık avcılığ 1 yasaktır. Diğer

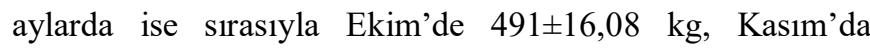

$469 \pm 18,31 \mathrm{~kg}$, Aralık'ta 426 $\pm 19,06 \mathrm{~kg}$, Ağustos’ta 410 $\pm 15,1$ $\mathrm{kg}$, Ocak'ta $103 \pm 6,07 \mathrm{~kg}$ ve Şubat'ta $101 \pm 5,51 \mathrm{~kg}$ balık avlandığı saptanmıştır (Şekil 3).

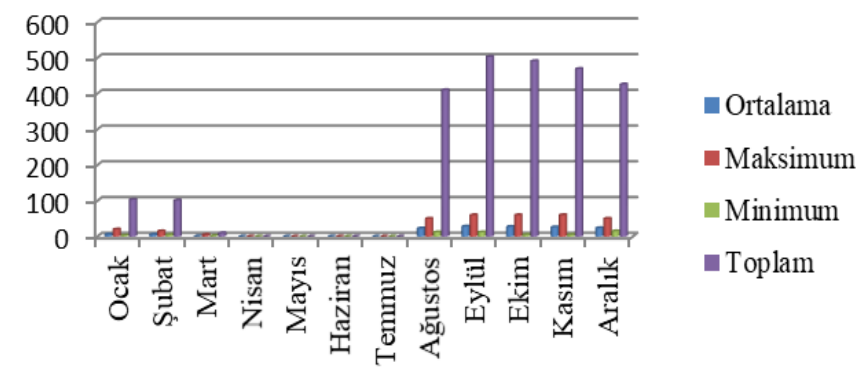

Şekil 3. Nazik Gölü’nde aylara göre avlanan balık miktarı (kg).

Avcılık Yapılan Gün Sayısı: Balıkçıların avcılığa çıktıkları ortalama gün sayısı incelendiğinde, en fazla

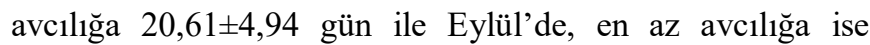
$1,10 \pm 2,74$ gün ile Mart ayında çıktıkları saptanmıştır. Diğer avcılığa çıktıkları ortalama gün sayısı ise sırası ile Ekim'de $19,77 \pm 4,80$ gün, Kasım'da 17,66 7,49 gün, Aralık’ta 
$15,33 \pm 10,28$ gün, Ağustos'ta $10,70 \pm 4,74$ gün, Şubat'ta $3,70 \pm 4,36$ gün ve Ocak'ta $3,60 \pm 4,37$ gün olarak tespit edilmiştir.

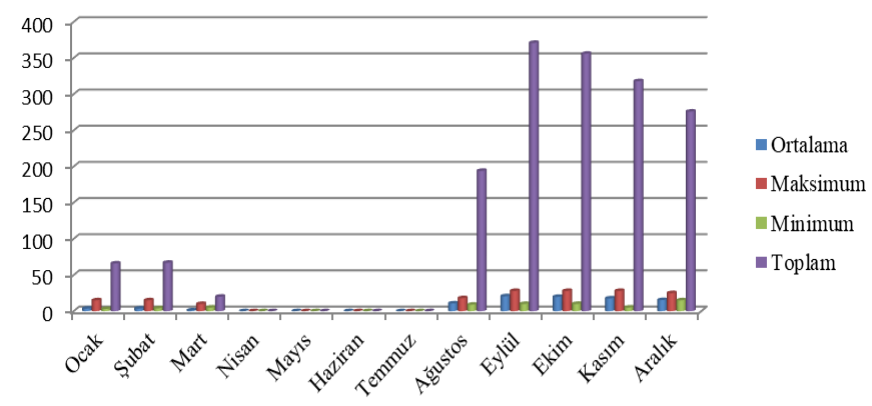

Şekil 4. Avc1lık yapılan gün sayısı

Avcılık Operasyon Bilgileri: Balıkçılarla yapılan anket sonuçlarına göre, ağların ortalama 18-20 saat suda kaldığ1 tespit edilmiştir. Genellikle saat 12:00 de atılan ağların ertesi sabah saat 6:00 da kaldırıldığı belirlenmiştir. Balıkçıların ağlarını 1-9 kulaç arasındaki derinliklere bıraktıkları belirlenmiştir. Balıkçı teknelerin hiçbirinde ağ tamburu olmadığı için ağların el ile atılıp toplandığ $\breve{g}_{1}$ tespit edilmiştir.

Balıkçıların Sosyo-Ekonomik Yapısı: Nazik Gölü'nde teknelerde çalışan tayfaların ortalama sayısı $1,22 \pm 0,73$ olarak tespit edilmiştir. Tayfaların \%83'ünün sürekli \%17'sinin ise arada bir çalıştığ çalışanların tamamının pay karşılığı çalıştığı tespit edilmiştir (Şekil 5).

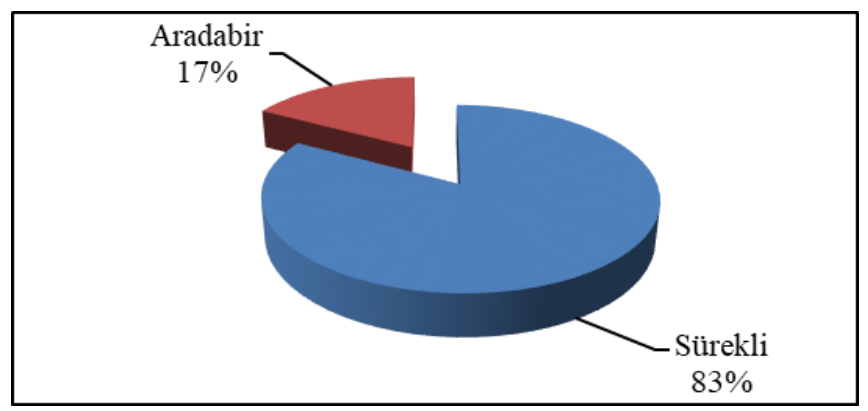

Şekil 5. Tayfaların çalışma şekli.

Nazik Gölü’nde balıkçıların \%78'inin ilkokul, \%22'sinin ortaokul mezunu olduğu saptanmıştır. Ayrıca çalışan balıkçılardan lise veya üniversite mezununun olmadığı tespit edilmiştir (Şekil 6).

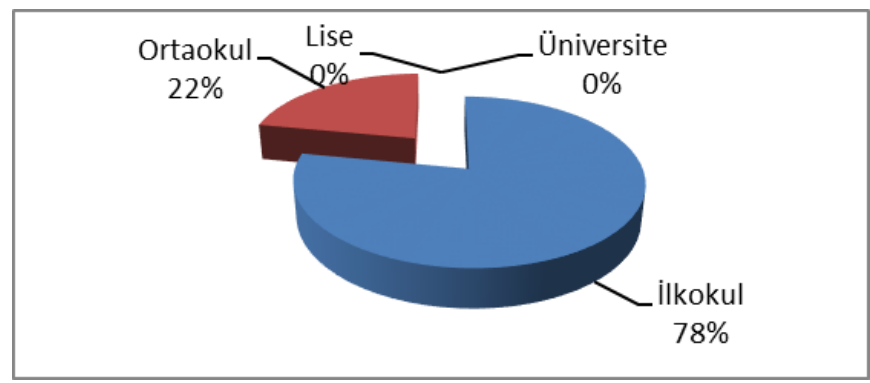

Şekil 6. Balıkçıların eğitim durumları.
Çalışmada, Nazik Gölü'nde balıkçılık yapanların ortalama yaşının $36,44 \pm 10,04$ olduğu, \%83'ünün evli ve

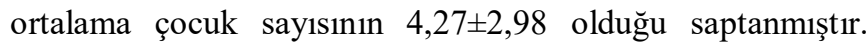
Balıkçıların \%95'inin ev sahibi olduğu tespit edilmiştir. Nazik Gölü'ndeki balıkçıların \%44'ünün baba mesleği olduğu için, \%17'sinin göl tutkusu nedeni ile \%39'unun ise başka bir iş imkânı olmadığı için zorunlu olarak balıkçılığa başladığı tespit edilmiştir (Şekil 7).

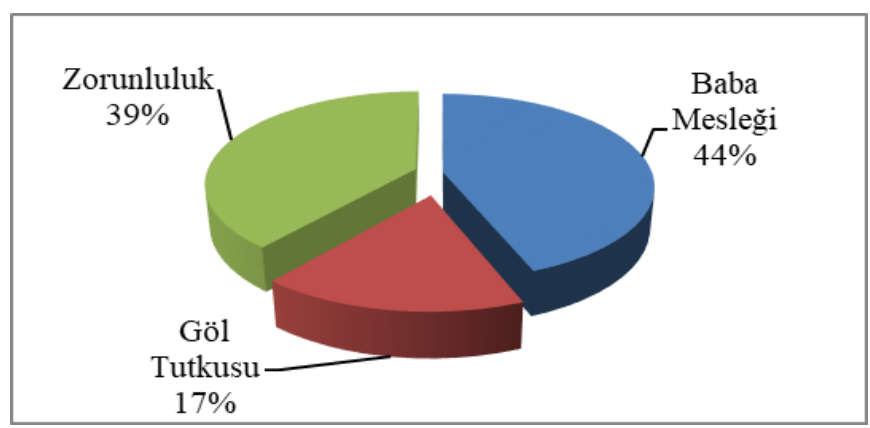

Şekil 7. Balıkçıların bu mesleğe nasıl başladıkları.

Nazik Gölü'nde balıkçıların \%89'unun sağlık sigortasının olmadığı, bunun yerine hepsinin yeşil kartının olduğu saptanmıştır. Balıkçıların büyük bir kesimi balıkçılığın devlet tarafından yeteri kadar desteklenmediğini beyan etmişlerdir. Balıkçılardan hiçbirinin balıkçılık kredisi kullanmadığ1 tespit edilmiştir. Tüm balıkçılar ürünlerini kooperatife verdiklerini beyan etmişlerdir. Pazarlamada en sık karşılaştıkları sorunun düşük fiyat olduğu saptanmıştır. Ankete katılan balıkçıların \%89'u çocuklarının bu işi yapmasını istemediğini belirtmişlerdir. Ayrıca balıç̧ıların \%61'inin balıkçılığı bırakmayı düşündükleri tespit edilmiştir. Balıkçıların en önemli sorunlarının kaçak avcılık ve avladıkları balığın düşük fiyata satılması olduğu tespit edilmiştir. Araştırma sonucuna göre balıkçıların hepsinin ikinci bir işinin olduğu belirlenmiştir. Özellikle sezonun kapalı olduğu dönemlerde çoğunluğunun inşaatta işçi olarak çalıştığı, bunun yanında hayvancılık ve tarımla da uğraştıkları tespit edilmiştir.

\section{TARTIŞMA ve SONUÇ}

Avlanan balığın büyük bir kısmını sazan ve sirazın oluşturduğu saptanmıştır. İç sularda yapılan araştırmalarda, Ulubat Gölünde 2006 yılında 642500 kg balık avlandığı saptanmıştır (Çınar, 2010). Atatürk Baraj Gölü Bozova Bölgesi'nde Şubat 1998-Nisan 1999 tarihleri arasında yapılan bir çalışmada 12 tür ve alt tür balığın avlandığı ve bunların bir avlanma sezonunda toplam $446701000 \mathrm{~kg}$ istihsal edildiği bildirilmektedir (Duman ve Çelik, 2001). Keban Baraj Gölü Pertek Bölgesinde 2008-2009 y1lı avlanma sezonunda yapılan bir araştırmada $154800 \mathrm{~kg}$ balık avlandığı belirlenmiştir. Nazik Gölü'nde avlanan balık miktarı bu çalışmalarda avlanan balık miktarlarına göre oldukça düşüktür. Göllerdeki balık miktarı sıcaklık, birincil üretim ve 
morfolojik yapı gibi ekolojik etkene bağlı olarak değişmektedir. $\mathrm{Bu}$ etkenler arasında sıcaklık en başta gelmektedir (Avşar, 2005). Nazik Gölü ülkemizin en soğuk bölgelerinden birisi olan doğu Anadolu Bölgesinde ve 1816 metre yükseklikte bulunmaktadır. Düşük sıcaklık sucul ortamlardaki birincil üretimi azaltmakta ve göllerin barındırabilecekleri balık miktarını azaltmaktadır (Kerkhoff vd., 2005). Nazik Gölü’nden avlanan balık miktarının diğer göllere göre düşük olmasının öncelikli nedeninin sıcaklı̆ga bağlı olarak verimliliğinin düşük olmasından kaynaklandığı düşünülmektedir. Ege bölgesinde bulunan Demirköprü Baraj Gölü'nde 2008 - 2015 yılları arasında avlanan sazan balığının yıllık ortalama $21292,5 \mathrm{~kg}$ olduğu bildirilmektedir (Șen, 2016). Nazik Gölü'nün yüzölçümü ile benzer olmasına rağmen avlanan balık miktarını çok düşüktür. Bu verilere bakarak Nazik Gölü'nün sazan ve siraz stoku yönünden verimli bir göl olduğunu söyleyebiliriz. Nazik Gölü’nde kullanılan ağlarını $70 \mathrm{~mm}$ ă̆ göz genişliğinde ve multiflament özelliğe sahip fanyalı uzatma ağlar olduğu saptanmıştır. Eğirdir Gölü’nde Aralık 2009-Nisan 2010 tarihleri arasında yapılan bir çalışmada $50,55,60$ ve $65 \mathrm{~mm}$ göz genişliğinde fanyalı uzatma ağlarının kullanıldığı bildirilmiştir (Çınar, 2010). Demirköprü Baraj Gölü’nde ticari balıkçıların sazan avcılığında $65,70,75,80 \mathrm{~mm}$ göz genişliğinde multifilament uzatma ağlarını kullandıkları belirlenmiştir (Şen, 2016). Cilbiz vd., (2015) tarafindan yapılan çalışmada, Manyas Gölü’ndeki sazan avcıllığında 50, $55,60,65$ ve $70 \mathrm{~mm}$ göz açıklığında fanyalı ağlar kullanıldığı bildirilmiştir. Nazik Gölü'nde kullanılan uzatma ağlarının ağ göz açıklığı diğer çalışmalarda kullanılan ağlara yakın olduğu tespit edilmiştir. Bu çalış̧malarda bazen daha küçük ağ göz genişliklerinin kullanılmasının nedeni ise çalışmanın farklı bir habitatta gerçekleştirilmesinden dolayı farklı balık boylarının olmasından kaynaklanmaktadır. Nazik Gölü'nde $32800 \mathrm{~m}$ fanyalı uzatma ağı kullanıldığı tespit edilmiştir. Keban Baraj Gölü Pertek Bölgesinde 69900 m multifilament ağ (galsama ağı+fanyalı ağ), $53500 \mathrm{~m}$ ise monofilament uzatma ağı kullanılmaktadır (Dartay vd., 2010). Keban Baraj Gölü'nün Nazik Gölü'ne göre 15 kat daha büyük olması nedeniyle kullanılan ağ uzunluğunun fazla olması beklenen bir durumdur. Balıkçıların sosyoekonomik yapıları incelendiğinde, Nazik Gölü’nde avcılık yapan balıkçıların ortalama yaşının $36,44 \pm 10,04$ olduğu tespit edilmiştir. Sağlam ve Karadal (2016) Akdeniz bölgesi için balıkçı yaşının \%56 oranında 31-50 yaş aralığında değiştiğini bildirmişlerdir. Dartay vd., (2010), Keban Baraj Gölü için yaptıkları çalışmada balıkçıların \%67'sinin 40-52 yaş aralı̆ı̆nda olduğunu belirtmişlerdir. Doğan ve Gönülal, (2011) tarafından Gökçeada için balıkçı yaşı 28-63, Yücel, (2006) Orta Karedeniz bölgesi için balıkçı yaşını 30-50 olarak bildirmiştir. Çalışmamız ile yapılan bu çalışmalar karşılaştırıldığında elde edilen bilgiler arasında benzer sonuçlar tespit edilmiştir.
Eğitim durumu incelendiğinde Nazik Gölü balıkçılarının \%78'inin ilkokul mezunu olduğu saptanmıştır. $\mathrm{Bu}$ oran yapılan benzer çalışmalarda, Doğan ve Gönülal (2011), Ege Bölgesindeki balıkçıların \%54,2'sinin ilkokul mezunu olduğunu bildirmiştir. Güngör vd., (2007), Tekirdağ ilindeki balıkçıların \%64,2'sinin ilkokul，\%22,2'sinin ortaokul, \%13,1'inin lise eğitimine sahip oldukları belirtilmiştir. Bu çalışmalarda tespit edilen eğitim durumları ile çalşmamızda saptanan eğitim durumları arasında benzerlik tespit edilmiştir. Bunun yanında İstanbul ili küçük ölçekli balıkçıların eğitim düzeyleri ise $\% 2,4$ 'ünün okuma yazma bilmediği, \%3,6'sının okur-yazar, \%40,1'inin ilkokul, $\% 17,4$ 'ünün ortaokul, $\% 26,3$ 'ünün lise ve $\% 10,2$ 'sinin üniversite mezunu olduğu bildirilmiștir (Doğan, 2009). Şahinler vd., (2005), Hatay (Samandağ) ilinde yaptıkları çalışmada balıkçıların \%7'sinin ilkokul, \%53'ünün ortaokul, $\% 26$ 'sının lise ve \%14'ünün ise yüksekokul-üniversite mezunu olduğunu bildirmişlerdir. Bu çalışmalarda tespit edilen eğitim durumları ile çalışmamızda tespit edilen eğitim durumları arasında farklılık tespit edilmiştir. Bu çalışmalarda elde edilen bulgularla Nazik Gölü'nde tespit edilen farklılıkların en önemli nedeninin bölgesel farklılıklardan kaynaklandığını düşünmekteyiz. Sosyal güvence durumları incelendiğinde, balıkçıların \%85'inin sağlık sigortasının olmadığı tespit edilmiştir. Orta Karadeniz Bölgesi balıkçılarının \%56'sının sosyal güvencesinin olduğu belirtilmiştir (Yücel, 2006). Keban Baraj Gölü Pertek Bölgesi balıkçılarının \%61,29'unun sosyal güvencesinin olmadığı bildirilmiştir (Dartay vd., 2009). Bu çalş̧malarda tespit edilen sosyal güvenlik durumları ile çalışmamızda saptanan sosyal güvenlik durumları arasında nispeten benzerlik tespit edilmiştir. $\mathrm{Bu}$ benzerliğin, bölgelerin yakın olmasından kaynaklandığı kanaatindeyiz. Gökçeada balıkçılarının $\% 62$ 'sinin sosyal güvencesinin olduğu bildirilmiştir (Doğan ve Gönülal, 2011). Akdeniz bölgesi sahil şeridi deniz balıkçılarının \%72'sinin sosyal sağlık kuruluşlarına üye oldukları belirtilmiştir (Sağlam ve Karadal, 2016). Bu çalışmalarda tespit edilen sosyal güvenlik durumları ile çalışmamızda saptanan sosyal güvenlik durumları arasında farklılık tespit edilmiştir. Bunun durumun, eğitim düzeyi ve kültürel farklılığa bağlı olarak farklı bir sosyal yaşantıya sahip olmasından kaynaklandığını düşünmekteyiz. Nazik Gölü’ndeki balıkçıların barınma durumları incelendiğinde, \%95'inin ev sahibi olduğu tespit edilmiştir. İskenderun bölgesi balıkçılarının \%72'sinin ev sahibi olduğu belirtilmiştir. Karadeniz bölgesi kıyı balıkçıları incelendiğinde, Artvin \%90, Rize \%89, Trabzon \%40, Giresun \%78, Ordu \%72, Samsun \%50, Sinop \%75'inin ev sahibi oldukları bildirilmiştir. Akdeniz bölgesi kıyı balıkçıllı̆ı için yapılan çalışmaya göre; Hatay ve Adana'daki balıkçıların \%60'ının, Mersin'dekilerin \%50'sinin, Antalya'dakilerin \%69'unun ev sahibi olduğu belirtilirken, kalan kısmın kiracı olduğu bildirilmiştir (Karadal, 2014). Nazik Gölü’nde çalışan balıkçıların büyük bir kısmının ikinci 
bir iş olarak inşaat, çiftçilik ve hayvancılıkla uğraştıkları tespit edilmiştir. Ayrıca balıkçılar, evlerini kendilerinin inşaa etmeleri nedeniyle evlerini düşük maliyete getirmektedirler. Ev sahiplik oranın yüksek olmasının önemli bir sebeplerinin de bu olduğu kanaatindeyiz. Balıkçıllğa nasıl başladınız sorusuna Nazik Gölü balıkçılarının \%40'ının baba mesleği, \%15'i göl tutkusu ve \% $\% 5$ 'i zorunluluktan cevabını vermiştir. Keban Baraj Gölü balıkçıları aynı soruya \%77 oranında işsizlikten, \%16'sı ise baba mesleği cevabını vermiștir (Dartay vd., 2009). Doğan, (2009) İstanbul balıkçıları ile yaptığı bir çalışmada \%44'ünün işsizlikten, \%15'inin hobi, \%14'ünün baba mesleğinden dolayı balıkçılığı seçtiklerini bildirmiştir. Doğan ve Gönülal, (2011) Gökçeada balıç̧ılığı için yaptıkları çalışmada balıkçıların \%45'lik bölümünün deniz kenarında yaşadıkları için balıkçılık yaptıklarını bildirmiştir. Sağlam ve Karadal, (2016) Akdeniz Bölgesi sahil şeridi balıkçıları ile yaptıkları çalışmada $\% 25$ 'inin baba mesleği olması nedeniyle işlerini sürdürdükleri, \%31'inin deniz tutkusundan kaynaklı hobi olarak balıkçılık yaptığını belirtmişlerdir. Bu çalışmalarda tespit edilen balıkçılığa nasıl başladığınız sorusuna verilen cevaplar ile çalışmamızda saptanan cevaplar arasında farkllılı tespit edilmiştir. Bunun en önemli nedeninin ise bu bölgelerde yaşayan balıkçıların farklı bir çevre ve kültüre sahip olmasından kaynaklandığını düşünmekteyiz. Ankete katılanların $\% 65$ 'i balıkçıllı̆ 1 bırakmak istemekte ve \%90'1 çocuklarının bu işi yapmasını istemediklerini beyan etmişlerdir. Buradan da açıkça görülmektedir ki Nazik Gölü balıkçıları balıç̧ılığın geleceğini iyi görmemektedirler. Bu nedenle Nazik Gölü balık kaynaklarının yönetilmesinde sürdürülebilir bir balıkçılık politikasının izlenmesinin yanında balıkçının da varlığını sürdürebilmesi için etkin ve doğru yönetim politikalarına ihtiyaç vardır. Nazik Gölü'nde balıkçılarla yapılan yüz yüze anket sonuçlarına göre balıkçıların en önemli sorunlarının kaçak avcılık olduğu tespit edilmiştir. Denizlerde ve iç sularda ticari amaçlı su ürünleri avcılığını düzenleyen $4 / 1$ numaralı tebliğe göre tüm iç sularda, girgır ve manyat ağlarının kullanılması yasaktır. Fakat Nazik Gölü’nde bu ağlar yoğun olarak kullanılmaktadır. Bu ağlar büyük balıkları yakalamalarının yanında, özellikle küçük boydaki bireyleri de avlayarak Nazik Gölü balık populasyonuna ciddi zararlar vermektedir. Yasal olarak avcılık yapan balıkçıların tamamının bu durumdan rahatsız olduğu belirlenmiştir. $\mathrm{Bu}$ konunun çözümü için kontroller arttırılmalı, daha caydırıcı cezalar uygulanmalıdır. Ayrıca, tüm toplumun bilinçlendirilmesi ile bu sorunun bir nebze çözüleceği kanaatindeyiz. Bir diğer sorun ise avlanan balığın düşük fiyata satılmasıdır. Bu durum içinde balıkçıların bir araya gelerek ortak hareket etmeleri veya balığa alternatif bir pazar bulunması olası bir çözüm olabilir. Unutulmamalıdır ki anket verileri tamamen balıkçılarla yüz yüze görüşme neticesinde alınmış bilgilerdir.

Sonuç olarak, olası bir yer, zaman veya kullanılan av araçlarının yasaklanması ya da miktarlarında yapılacak bir kısitlama durumunda ilgili yöneticilerin öncelikle yerinde araştırma yaparak durumu tespit etmek ve gerekirse balıkçının resmi beyanlarından yararlanmak daha akılcı bir yaklaşım olacaktır. Nazik Gölü'nde balık stokunun korunması ve sürdürülebilir bir balıkçılık için ekolojik ve biyolojik verilerin yanında sosyo-ekonomik verilerin de izlenmesi ve sürekli olarak yenilenmesi gerekmektedir.

\section{KAYNAKLAR}

Alkışlar, H. Meydan, A.M., Kalugin, I., Çağatay, M.N., Darin, A., Akkol, S., Rudaya, N., Meydan, İ., Rogozin, D. \& Demir, H. (2017). Nazik Gölü dip sedimanlarının tane boyu dağılımı. 70. Türkiye Jeoloji Kurultayı 2017 (s. 96). Ankara, Türkiye: Bildiriler Kitabı.

Avşar, D. (2005). Balıkçllı Biyolojisi ve Populasyon Dinamiği. Nobel Yayınevi, Adana, Türkiye, 303s.

Cilbiz, M., Küçükkara, R., Ceylan, M., Savaşer, S. \& Meke, T. (2015). Trammel net selectivity of common Carp (Cyprinus carpio L., 1758) in Manyas Lake, Turkey. Journal of Limnology and Freshwater Fisheries Research, 1(1), 1-7.

Çınar, Ş. (2010). Eğirdir Gölü’nde Monofilament (Tek Kat) Ve Multiflament (Çok Kat) Fanyalı Ağların Av Verimliliklerinin Karşılaştırılması. Süleyman Demirel Üniversitesi Fen Bilimleri Enstitüsü, Isparta, Türkiye, 93s.

Dartay, M., Duman, E. \& Ateşşahin, T. (2010). Keban Baraj Gölü Pertek bölgesi uzatma ağları balıkçılığı ve av verimi. Journal of Fisheries Sciences.com, 4(4), 384-390.

Dartay, M., Duman, E., Duman, M., \& Ateşşahin, T. (2009). The socio-economic analysis of fishermen Pertek region in Keban Dam Lake. Ege Journal of Fisheries and Aquatic Sciences, 26(2), 135-138.

Doğan, K. \& Gönülal, O. (2011). Fisheries of Gökçeada Island (Aegean Sea) and socio-economic structure of fishermen. The Black Sea Journal of Science, 2(5), 57-69.

Doğan, K. (2009). İstanbul ilinde küçük ölçekli balıkçıllğın sosyo-ekonomik analizi. Ulusal Su Günleri 2009 Sempozyumu 2009 (s 93). Elazı̆g, Türkiye: Bildiriler Kitab1.

Duman, E. \& Çelik, A. (2001). Atatürk Baraj Gölü Bozova Bölgesi'nde avlanan balıklar ve verimlilikleri. Ege Journal of Fisheries and Aquatic Sciences, 18(1-2), 65-69.

Güngör, G., Özen, S.Ş. \& Güngör, H. (2007). The socioeconomic structure of fishery activities and seafood marketing in Marmara Sea: A case study along the coastal area of Tekirdağ province. Journal of Tekirdag Agricultural Faculty, 4(3), 311-325. 
Karadal, E. (2014). Akdeniz bölgesi (Türkiye) sahil şeridi deniz balıkçılığının sosyo-ekonomik durumu. Doktora Tezi, Ordu Üniversitesi Fen Bilimleri Enstitüsü, Ordu, Türkiye, 133s.

Karakuş, Y. (2015). Avrupa Birliği'nde küçük ölçekli balıkçılığın sosyo-ekonomik durumu, yönetimi ve Türkiye ile karşılaştırılması. AB Uzmanlık Tezi, Gıda, Tarım ve Hayvancılık Bakanlığı, Avrupa Birliği ve Dış İlişkiler Genel Müdürlüğü, Ankara, Türkiye.

Kerkhoff, A.J., Enquist, B.J., Elser, J.J., \& Fagan, W.F. (2005). Plant allometry, stoichiometry and the temperature-dependence of primary productivity. Global Ecology and Biogeography, 14(6), 585-598.

Özbilgin, Y., Gökçe, G., Özbilgin, H., Çelik, O., Ünal, V. \& Tokaç, A. (2007). "Kuzeydoğu Akdeniz balıkçılığının yapısal analizi”, Mersin Üniversitesi Bilimsel Araştırma Projeleri, BAP-SÜF AGT (YÖ) 2007-1, (2009).

Sağlam, N. \& Karadal, E. (2016). Akdeniz Bölgesi sahil şeridi deniz balıkçılığının sosyo-ekonomik yapısı. Süleyman Demirel Üniversitesi Eğirdir Su Ürünleri Fakültesi Dergisi, 12(2), 158-169.

SUBİS, (2018). Su ürünleri bilgi işlem sistemi. http://subis.tarim.gov.tr/. (Erişim: 17.09.2018).

Şahinler, S., Can, M.F., Görgülü, Ö. \& İğne, K.D. (2005). Samandağ ilçesinde (Hatay) balıkçılığın genel durumu, sorunları ve çözüm önerileri üzerine bir araştırma. Fırat Üniversitesi Fen ve Mühendislik Bilimleri Dergisi, 17(4), 605-615.

Şen, F. (2001). Nazik gölü (Ahlat-Bitlis) sazan (Cyprinus carpio L., 1758) populasyonu üzerine bir araştırma (Ahlat-Bitlis-Türkiye). Atatürk Üniversitesi Doktora Tezi, Erzurum, Türkiye.140s.
Şen, Y. (2016). Demirköprü baraj gölü'nde sazan (Cyprinus carpio L., 1758) türü için kullanılan uzatma ağlarının av verimliliği ve seçiciliğinin belirlenmesi. İzmir Katip Çelebi Üniversitesi Fen Bilimleri Enstitüsü. Yüksek Lisans Tezi, İzmir, Türkiye.79s.

Tokaç, A., Ünal, V., Tosunoğlu, Z., Akyol, O., Özbilgin, H. \& Gökçe, G. (2007). Ege Denizi balıkçılığının yapısal analiz. Ege Üniversitesi Bilimsel Araştırma Projeleri. 2002/SÜF/006, 161 s. Bornova, Türkiye.

TÜIK, (2018). Türkiye İstatistik Kurumu. https://biruni.tuik.gov.tr/medas/?kn=97\&locale $=$ tr (Erişim:12.09.2018).

Ünal, V. (2003). Yarı zamanlı küçük ölçekli balıkçılığın sosyo ekonomik analizi, Foça (Ege Denizi). Ege Journal of Fisheries and Aquatic Sciences, 20(1-2), 165-172.

Ünal, V., Akyol, O. \& Hoşsucu, H. (2001). Requirements for bio-economic data in fisheries management. Ege Journal of Fisheries and Aquatic Sciences, 18(1-2), 243-253.

Yücel, Ş. (2006). Middle Black Sea region fishing and socioeconomic status of fishermen. Ege Journal of Fisheries and Aquatic Sciences, 23(1-3), 529-532.

*Corresponding author's: Adem Sezai BOZAOĞLU

Van Yüzüncü Yıl Üniversitesi Su Ürünleri Fakültesi, 65080, Zeve Kampüsü, Van, Türkiye.

\-mail: sbozaoglu@ hotmail.com

ORCID : https://orcid.org/0000-0003-4078-5159

GSM : : +90 (533) 6352345 